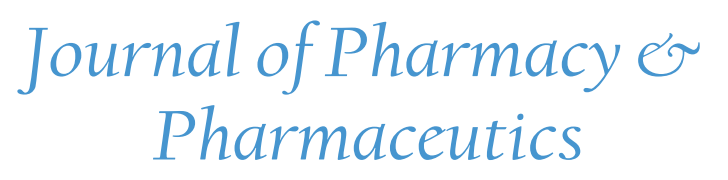

\title{
A Survey on Cervical Cancer and its Vaccination in Chittagong City, Bangladesh
}

\author{
Md. Shahidul Islam*, Mohammed Enamul Hoque, Nazia Nowrin
}

Department of pharmacy, University of Science and Technology Chittagong

"Corresponding author: Md. Shahidul Islam, Assistant Professor, Department of Pharmacy, University of Science \& Technology Chittagong (USTC), E-mail: s_i_liton@yahoo.com

\begin{abstract}
Cervical cancer is one of the most common cancers in all over the world. Cervical cancer is a kind of cancer that starts in the cervix which is the lower part of the uterus that opens into the vagina. Cervical cancer is usually found at a very early stage through a Pap test \& HPV test. Data regarding the result PAP test and vaccination were collected and a qualitative questionnaire based survey among 100 students aged $16-25$ years was conducted. $65 \%$ young women know about the cancer as well as the risk factors but the level of knowledge regarding prevention is low (24\%). Low frequency (39\%) women are having preventive methods like regular PAP smear screening and HPV vaccine. The most effective age to get vaccinated is 10 to 25 but the young woman among this age doesn't have proper knowledge about the vaccination. The mostly given vaccine in the Chittagong city is CERVARIX.
\end{abstract}

Keywords: Cervical Cancer; HPV infection; PAP test; HPV Vaccination
Received date: August 27, 2016

Accepted date: August 16, 2017

Published date: August 21, 2017

Citation: Md. Shahidul Islam., et al. A Survey on Cervical Cancer and its Vaccination in Chittagong City, Bangladesh. (2017) J Pharm Pharmaceutics 4(2): 133- 137.

DOI: $10.15436 / 2377-1313.17 .024$

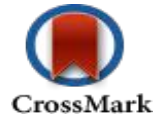

\section{Introduction}

Currently Cervical cancer is a burning issue around the world. Now annually approximately 510,000 new cases of cervical cancer has been reported \& approximately 288,000 deaths worldwide $^{[1]}$. Cervical cancer occurs in the early hours and impacts at the fruitful period of a woman's life ${ }^{[2]}$. The incidence rises in $30-34$ years of age and peaks at $55-65$ years, with a median age of 38 years (age $21-67$ years).It is reported that more than $80 \%$ of the sexually active women gain genital HPV by 50 years of age $^{[3]}$.

It should be mentioned that the mortality has abridged due to introduction of population-based cytological screening program by using Pap test in developed countries. So screening for cervical infection of HPV has become to be more efficient, effective and dependable ${ }^{[4,5]}$. Now it is observed that two HPV vaccines bivalent "Cervarix" is highly effective in preventing infection with high-risk type HPV16 and HPV18 ${ }^{[6]}$.

Recently it is showed that cervical cancer is the most common cancer in developing countries like India \& Bangladesh. About $22-29 \%$ of the women are affected by cervical cancer in different areas of Bangladesh ${ }^{[7,8]}$. A recent review showed that teen age period had very poor knowledge about HPV vaccination. So they cannot take vaccine. But some studies has shown at parental willingness to vaccinate their children ${ }^{[9,10]}$. It should be mention that very few studies have reported the knowledge of HPV vaccine, attitudes and intentions of young women ${ }^{[11]}$.

In Bangladesh the awareness \& knowledge of HPV 
vaccine \& cervical cancer is very poor ${ }^{[12]}$. In view of this, A study from city among nursing staff showed that $74 \%$ know PAP smear is used for detection of cervical cancer, only 59\% know pap smear can detect both cancerous and precancerous lesions of cervix. Astonishingly, only $18 \%$ has knowledge about HPV vaccine $^{[13]}$.

\section{Materials and Methods}

Type of study: It was descriptive type of cross sectional study with one step satisfaction.

Place of study: The present study was carried out in the Eagle Diagnostic Center, the community medicine department of Chittagong Medical College Hospital, Chittagong Ma-O-Sishu Hospital \& Medical College and the Chittagong Government Women College.

Data Collection Period: From $1^{\text {st }}$ April 2015 to $15^{\text {th }}$ June 2015.

Sample \& Sampling Technique: Data of PAP smear screening result were collected from a diagnostic center and the data from different Vaccination center regarding cervical cancer vaccination were used as materials to carry out the survey. A questionnaire was designed to collect young women's socio demographic characteristics and to assess their knowledge about cervical cancer and its prevention. Collecting the filled up questionnaire, the answer were showed the perception about the level of knowledge about the cervical cancer and its vaccination.

Survey the result of the PAP smear screening: Data of 100 patients regarding the PAP smear screening were collected from a diagnostic center. The data shows the name and age of the patients, authorized doctor, their disease and the result of PAP smear test.

Survey of the level of knowledge about the cervical cancer among the students of college and universities by using questionnaire: A pre-designed questions were delivered among the 110 young women of the college aged between 16 to 25 years were enumerated. First part of the questionnaire was to collect information on age, study stream, level of study were noted. The remaining part a self-administered questionnaire was used for this study, which were to be filled in individually by the participants under the strict vigilance of the teachers or mentors which serves as invigilators to monitor the influence on answers by the students. The questionnaire contained questions regarding knowledge of cervical cancer, HPV and awareness about HPV vaccine. In addition, there is question on parent's opinion about HPV vaccine acceptance. The questions were developed based on previous established facts for cervical cancer ${ }^{[7]}$. The data from questionnaire were processed anonymously. Data were analyzed to assess the association between demographic factor, cervical cancer awareness and prevention.

\section{Results}

PAP Smear Test: PAP smear test is a diagnostic procedure that checks the condition of cervix. This test looks for cancer and the precancerous condition. Although it is a preventive way for cervical cancer, the reasons why women get their PAP smear screening can be viewed from different aspects, as summarized in figure 1.

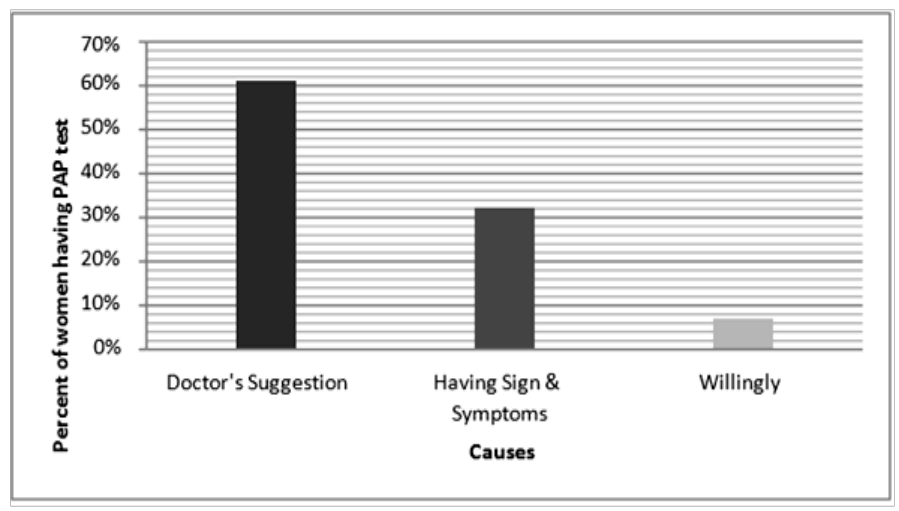

Figure 1: Percent of women having PAP test.

Comment: $74 \%$ of women are getting PAP smear test after doctor suggestion, after having sign \& symptoms but only $7 \%$ women willingly come to have the test.

\section{Results of PAP smear Screening:}

The chronic cervitis mostly go for the PAP test. The results come out in four categories on the basis of their cervix condition. The normal study confirms that there is no inflammation. The mild inflammation can be treated with the anti-inflammatory drugs whereas moderate inflammation requires further PAP test along with the anti-inflammatory drugs. The Severe inflammation indicates the precancerous condition that would go for the biopsy test (Figure 2) (Figure 3).

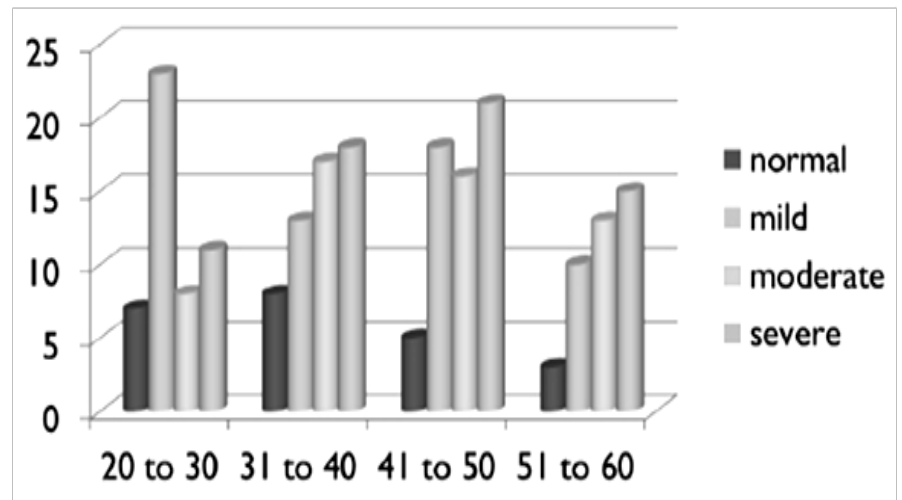

Figure 2: Chart of the result of PAP screening of 100 women.

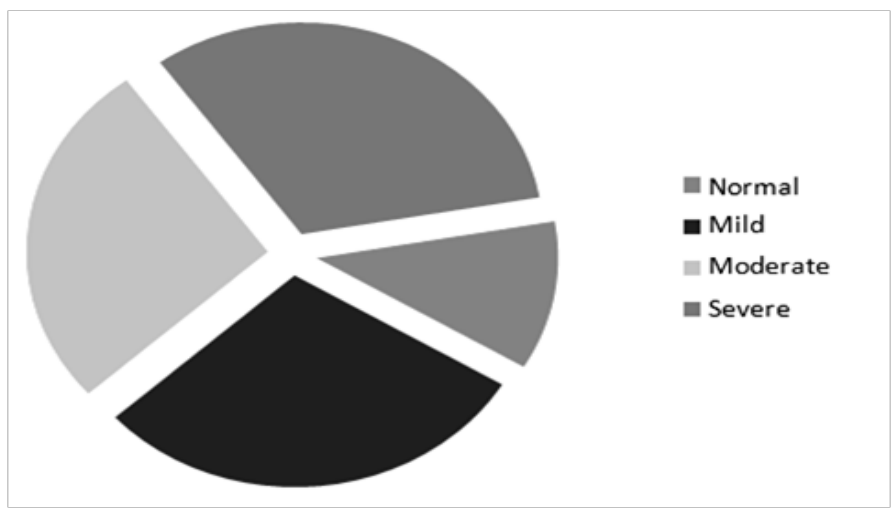

Figure 3: Percent of disease condition women usually get. 
Comments: In every range of aged women are often get inflammation, 23\% women are free from any inflammation, $60 \%$ women have mild inflammation, $54 \%$ are moderately got inflammation and $65 \%$ women having severe condition.

\section{Vaccination:}

There are two vaccines are available in market. The generally used vaccine is the CERVARIX, product of GlaxoSmithKline.

Table: Mostly used Vaccine:

\begin{tabular}{|l|l|}
\hline CERVARIX & $99 \%$ \\
\hline GARDASIL & $1 \%$ \\
\hline
\end{tabular}

\section{HAVING THE VACCINE:}

In our country, there are very few women having the HPV vaccine. The women having vaccine due to- (Figure 4)

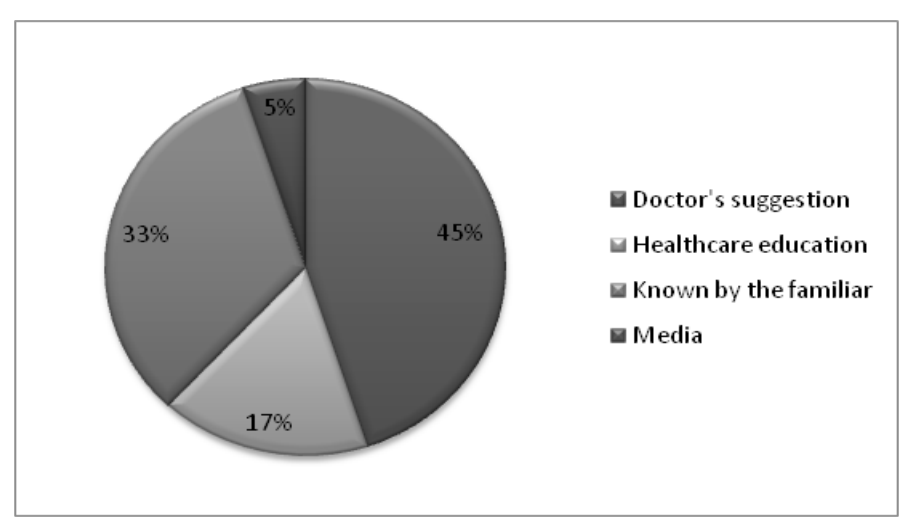

Figure 4: Causes of having vaccine.

Comment: Doctor often suggest to get the vaccine to $45 \%$ women, $17 \%$ medical student get vaccine, $5 \%$ influenced by media and rest of the women known from their familiar.

\section{Ages of women having Vaccination:}

The effective age of getting HPV vaccine is in between 10 to 44 years old and it is mostly effective before sexual exposure. (Figure 5)

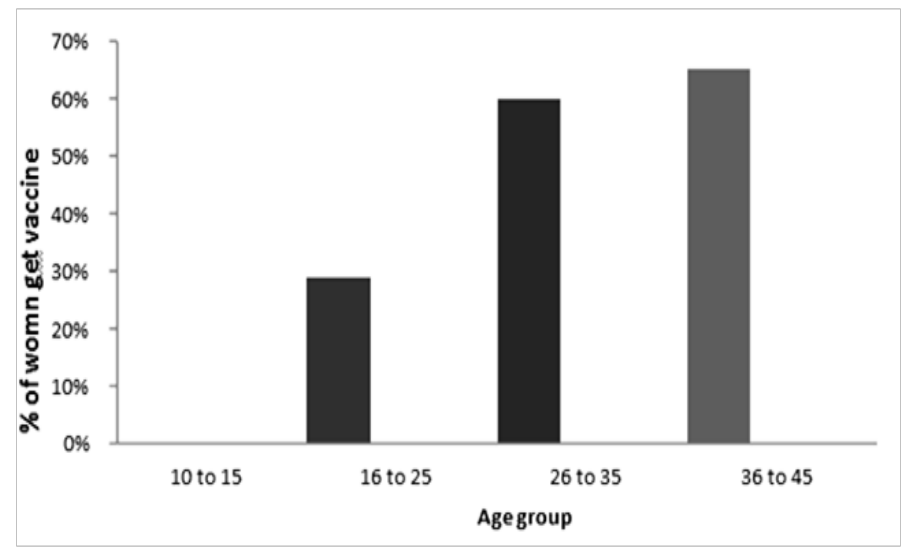

Figure 5: Age distribution chart for women having vaccine.

Comment: None of girl get vaccine in the age between 10 to 15 , but $60 \%$ young women who are belong to age between 26 to 35 get vaccine whereas $65 \%$ women in 35 to 45 have vaccine.
Demographic characteristics of young women: (Figure 6)

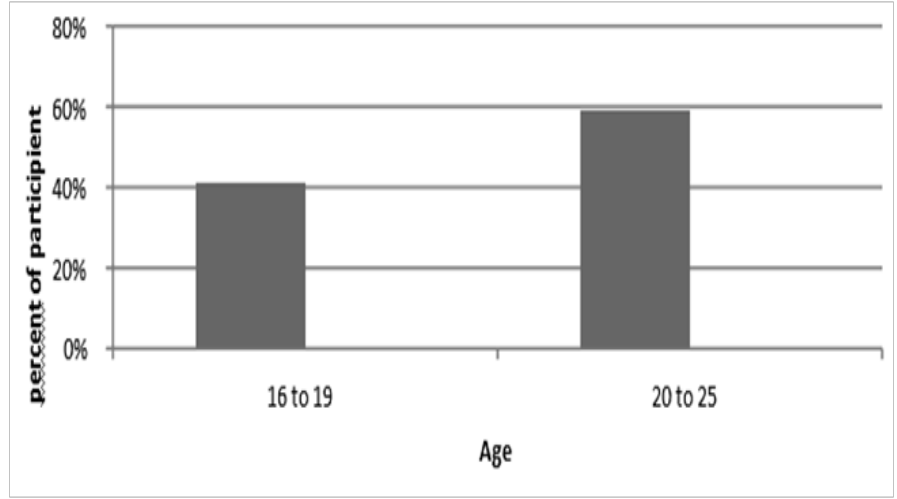

Figure 6: Age distribution of the participants.

Educational qualification of the participants: (Figure 7)

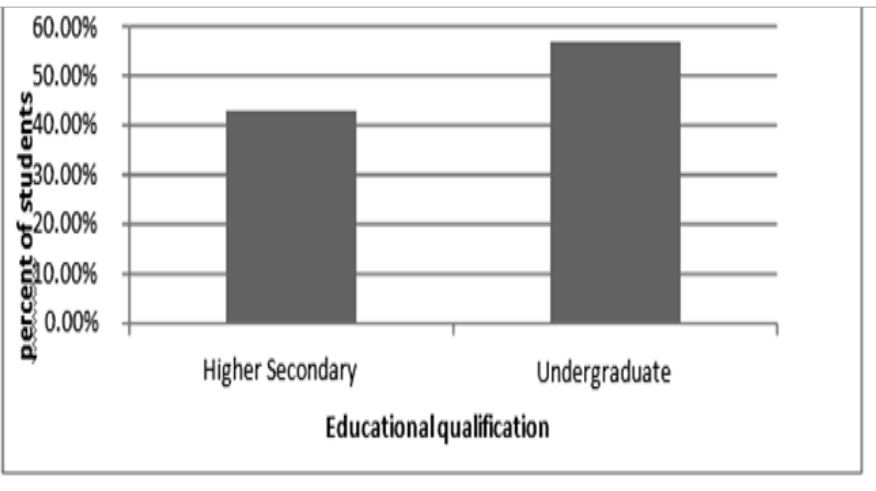

Figure 7: Educational qualification of the participants.

\section{Knowledge about cervical cancer:}

Cervical cancer is a common cancer for women. Nowadays it become rises rapidly so that young women should know about the cancer. (Figure 8)

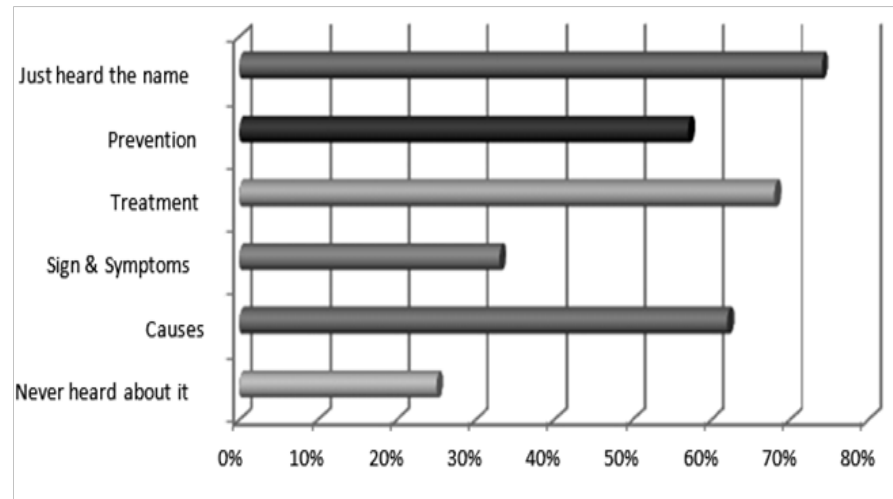

Figure 8: Chart about the knowledge of the cancer.

Comments: $74 \%$ young girls know almost about the cervical cancer but $25 \%$ never heard about it let alone the other factors. 


\section{Knowledge about the Risk Factors (Figure 9)}

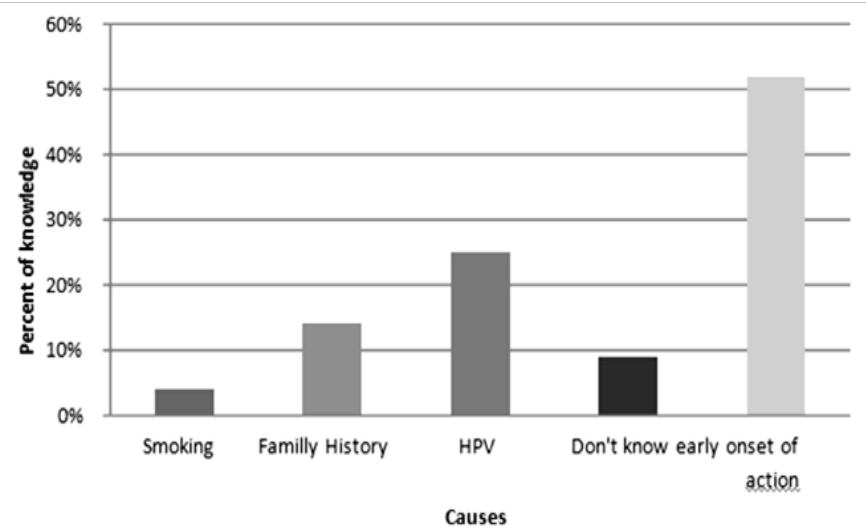

Figure 9: Percent of student have the knowledge about the risk factors.

Comments: Maximum student knows that this is a sexually transmitted diseases (52\%) where 9\% doesn't have any idea about the risk factors.

\section{Knowledge about preventive ways:}

Complete safety can be assured by taking the prevention. Mostly the HPV vaccination can be the first choice of prevention. (Figure 10)

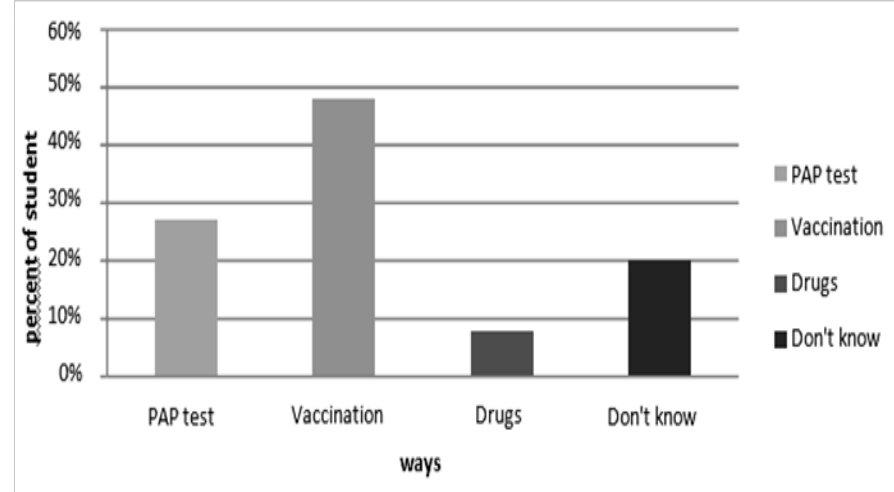

Figure 10: Percent of student have the knowledge about the preventive ways.

Comment: $48 \%$ young student know about the vaccine as the preventive ways besides $29 \%$ know about the PAP smear screening but $20 \%$ don't know about any preventive ways.

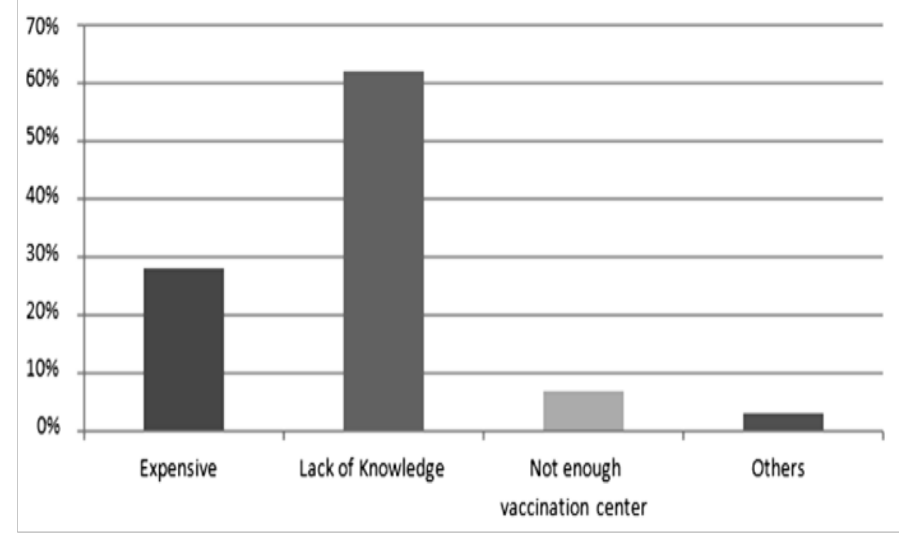

Figure 11: Percentage of student's opinion for not having vaccine.

\section{Causes not having vaccination:}

The young girls who know about the HPV vaccination as the primary preventive ways but they don't get vaccine due to some reasons. (Figure 11)

Comments: $62 \%$ young girls have lack of knowledge about vaccination, $28 \%$ young girls couldn't get vaccine due to expenses moreover $7 \%$ informed that every vaccination center doesn't provide the cervical cancer vaccine.

\section{Discussion}

As per our knowledge the study is to evaluate the knowledge of the cervical cancer, HPV and its vaccination as preventive methods. The regular PAP smear test also a prevention methods. In the present study, $61 \%$ women get their vaccine after doctor's suggestion, the result of the PAP smear screening shows that $65 \%$ got severity as their pre-cancerous condition. The vaccination is assured the complete safety against the HPV infection. Cervarix is the choice of vaccine in the city. The medical students $(71 \%)$ are more conscious than the other graduate $(29 \%)$. The vaccine is most effective before the sexual exposure, in the age between 16 to 25 but the vaccine is not generally among the women who are aged between 36 to $45(65 \%)$.

A pre designed questionnaire helps to find out the level of the awareness and knowledge about the cervical cancer among the young educated women. $74 \%$ know about the cancer whereas $48 \%$ choose the vaccine as their preventive methods. But they don't get the vaccine due to the expenses (28\%), lack of detail knowledge $(62 \%)$ also a reason not to vaccine. Comparing the developed countries young girls $(87 \%)$ are already gets vaccinated in contrast in our society yet it is not introduced much.

\section{Conclusion}

This study talks about the testing, diagnosis, and treatment of cervical cancer. As we can say that complete safety can be assured by taking the prevention. So, mostly the HPV vaccination can be the first choice of prevention. However, mass media campaign can enhance healthy behaviors and can track the diffusion of adequate knowledge.

Acknowledgement: we would like to express our heartfelt gratitude to the authority of University of Science \& Technology Chittagong for providing support to conduct the study. 


\section{References}

1. Schiffman, M., Castle, P.E., Jeronim, J., et al. Human papillomavirus and cervical cancer. (2007) Lancet 370(9590): 890-907.

Pubmed | Crossref | Others

2. Sankaranarayanan, R., Ferlay, J. Worldwide burden of gynecological cancer: The size of the proble. (2006)Best Pract Res Clin Obstet Gynaecol 20(2): 207-225.

Pubmed | Crossref | Others

3. Singh N. HPV and Cervical cancer - prospects for prevention through vaccination. Indian J Med Paediatr Oncol (2005) 26(1): 20-23.

Pubmed $\mid$ Crossref $\mid$ Others

4. Castellsagué, X., Schneider, A., Kaufmann, A.M., et al. HPV vaccination against cervical cancer in women above 25 years of age: key considerations and current perspectives. (2009) Gynecologic Oncology 115(3 Suppl): S15-S23

Pubmed | Crossref | Others

5. Paavonen, J. Human Papillomavirus infections and the development of cervical cancer and related genital neoplasias. (2007) Int J Infect Dis 11(Suppl 2): S3-S9.

Pubmed | Crossref | Others

6. Kim, J.J., Ortendahl, J., Goldie, S.J. Cost-effectiveness of human papillomavirus vaccination and cervical cancer screening in women older than 30 years in the United States. (2009) Ann Intern Med 151(8): 538-545.

Pubmed | Crossref | Others

7. Singhal T., Amdekar, Y.K., Agarwal, R.K., et al. Indian Academy of Pediatrics Committee on Immunisation (IAPCOI). Consensus Recommendations on Immunization. (2008) Journals of Indian Pediatr 45(8): 635-648.

Pubmed $\mid$ Crossref $\mid$ Others

8. Maruf Siddiqui. Cervical Cancer Vaccination: A New Hope. (2011) Anwer Khan Modern Medical College Journal 2(1): 26-31.

Pubmed $\mid$ Crossref $\mid$ Others

9. Myers, E.R., McCrory, D.C., Nanda, K., et al. Mathematical model for the natural history of human papillomavirus infection and cervical carcinogenesis. (2000) Am J Epidemiol 151(12): 1158-1171.

Pubmed | Crossref | Others

10. Ferenczy, A., Franco, E. Cervical-cancer screening beyond the year 2000. (2001) Lancet Oncol 2(1): 27-32.

Pubmed | Crossref | Others

11. Lenselink, C.H., Gerrits, M.M., Melchers, W.J., et al. Parental acceptance of Human Papillomavirus vaccines. (2008) Eur J Obstet Gynecol Reprod Biol 137(1): 103-107.

Pubmed | Crossref | Others

12. Ogilvie, G.S., Remple, V.P., Marra, F., et al. Parental intention to have daughters receive the human papillomavirus vaccine. (2007) CMAJ 177(12): 1506-1512.

Pubmed | Crossref | Others

13. Sperber, N.R., Brewer, N.T., Smith, J.S. Influence of parent characteristics and disease outcome framing on HPV vaccine acceptability among rural, Southern women. (2008) Cancer Causes Control 19(1): 115-118.

Pubmed | Crossref | Others

Ommega Online Publishers

Journal Title: Journal of Pharmacy \& Pharmaceutics

Journal Short Name: J Pharm Pharmaceutics
Journal ISSN: 2377-1313

E-mail: pharmacoinformatics@ommegaonline.com

Website: www.ommegaonline.org 